\title{
Health - related quality of life of Kuwaiti women with breast cancer: a comparative study using the EORTC Quality of Life Questionnaire Shafika A Alawadi ${ }^{1}$ and Jude U Ohaeri*2
}

Address: ${ }^{1}$ Department of Medicine, Faculty of Medicine, Kuwait University, Kuwait and ${ }^{2}$ Department of Psychiatry, Psychological Medicine Hospital, Gamal Abdul Naser Road, PO Box 4081, Safat, 13041, Kuwait

Email: Shafika A Alawadi - alawadish@yahoo.com; Jude U Ohaeri* - judeohaeri@hotmail.com

* Corresponding author

Published: 8 July 2009

BMC Cancer 2009, 9:222 doi:10.1 |86/|47|-2407-9-222
Received: 3 April 2009

Accepted: 8 July 2009

This article is available from: http://www.biomedcentral.com/I47I-2407/9/222

(c) 2009 Alawadi and Ohaeri; licensee BioMed Central Ltd.

This is an Open Access article distributed under the terms of the Creative Commons Attribution License (http://creativecommons.org/licenses/by/2.0), which permits unrestricted use, distribution, and reproduction in any medium, provided the original work is properly cited.

\begin{abstract}
Background: The Kuwaiti perspective on quality of life (QOL) in breast cancer is important because it adds the contribution from a country where the disease affects women at a relatively younger age and seems to be more aggressive. We used the EORTC QLQ - C30 and its breastspecific module (BR-23) to highlight the health-related QOL of Kuwaiti women with breast cancer, in comparison with the international data, and assessed the socio-demographic and clinical variables that predict the five functional scales and global QOL (GQOL) scale of the QLQ - C30.
\end{abstract}

Methods: Participants were consecutive clinic attendees for chemotherapy, in stable condition, at the Kuwait Cancer Control Center.

Results: The 348 participants were aged 20-8I years (mean 48.3, SD 10.3); 58.7\% had stages III and IV disease. Although the mean scores for QLQ - C30 (GQOL, 45.3; and five functional scales, $52.6 \%-61.2 \%$ ) indicated that the patients had poor to average functioning, only $5.8 \%$ to $11.2 \%$ had scores that met the $</=33 \%$ criterion for problematic functioning, while $12.0 \%$ to $40.0 \%$ met the $>66 \%$ criterion for more severe symptoms. Most (47.8\%-70.1\%) met the $>66 \%$ criterion for "good functioning" on the BR-23 functional scales. The mean scores of the QLQ - C30 indicated that, despite institutional supports, Kuwaiti women had clinically significantly poorer global QOL and functional scale scores, and more intense symptom experience, in comparison with the international data (i.e., $</=10 \%$ difference between groups). For the BR-23, Kuwaiti women seemed to have clinically significantly better functional scale scores, but more severe symptoms, especially systemic side effects and breast symptoms. Younger women had poorer HRQOL scores. In regression analysis, social functioning accounted for the highest proportion of variance for GQOL.

Conclusion: The relatively high number that met the criterion for good functioning on the functional scales is an evidence base to boost national health education about psychosocial prognosis in cancer. In view of the poor performance on the symptom scales, clinicians treating Kuwaiti women with breast cancer should prepare them for the acute toxicities of treatment and address fatigue. The findings call for the institution of a psycho-oncology service to address psychosocial issues. 


\section{Background}

In the field of medicine, one popular definition of the construct of quality of life (QOL), based on the World Health Organization's definition of health, is that it concerns physical, psychological and social functioning, incorporating positive aspects of wellbeing as well as negative aspects of disease [1] Health - related QOL (HRQOL) is that aspect attributable to the disease and its treatment, and generally consists of assessments of functional health status (i.e., limitations on physical, psychological and social functioning imposed by the disease) and global wellbeing [2].

Although there has been considerable research on the QOL of women with breast cancer [3], the results may not be significantly affecting clinical decision - making because the clinical significance of findings is not specified $[4,5]$. More studies are therefore needed to make QOL assessment feasible, understandable and scientifically viable in oncology research and practice [5]. In particular, HRQOL assessments in oncology facilitate doctor patient communication, they point to areas where patients may experience serious problems, they can be used as diagnostic tools for problem- oriented follow - up care, and the data are strong predictors of survival $[6,7]$.

These issues are highly relevant in Arab countries, such as Kuwait, where there is paucity of studies on QOL in cancer $[8,9]$, and the development of modern oncology services has led to improved survival rates, thereby making the disease to be a chronic condition. In addition, there are indications that different cultural groups may emphasize different aspects of their QOL [10]. For example, analysis of a large international database of the European Organization for Research and Treatment in Cancer Quality of Life Questionnaire (EORTC QLQ - C30) indicated that, compared with subjects from the UK, physical and social functioning were less important in predicting the global QOL of subjects from Islamic countries, while cognitive functioning was more influential for South Asia and Latin America [10]. This obviates the need to assess the local perspectives on international QOL instruments, so that the data can be used to guide the choice of interventions and for cross-cultural comparisons to contribute to the emerging QOL theory [11]. Accordingly, researchers have sought to highlight the factors that predict HRQOL among women with breast cancer. The common findings are as follows: First, younger age and chemotherapy are risk factors for diminished QOL [12-16]. Second, the association of stage of breast cancer with QOL is more controversial, with some authors finding no significant relationship [15,17], while others report significant impact, in line with expectation of known groups validity $[3,9,18,19]$. Also controversial is the impact on QOL, of the type of breast surgery $[12,14,15]$, and time since sur- gery and chemotherapy $[12,20]$. Third, disease - free women tend to have global QOL scores similar to the general population [21].

In this study, we sought to present an Arab perspective on the above issues, by using the EORTC QLQ - C30 [17] and its breast cancer specific module (BR -23) [18] to assess women attending the outpatient service of the Kuwait Cancer Control Center (KCCC) for chemotherapy. We chose the EORTC QLQ for the following reasons. First, although it was articulated in Europe, it has been found to be reliable and valid in diverse cultures, including, the United Arab Emirates [9], Iran [19], Turkey [22], Japan [23], India [13], China [24], Korea [25], and Nigeria [26]. Hence, there is an impressive body of international data with which to compare our results. Second, an Arabic translation of the questionnaire already exists, approved by the authors of the instrument.

The Kuwaiti perspective is important because it adds the contribution from a country where the pathobiological features of the disease indicate that it affects women at a relatively younger age and it seems to be more aggressive than what is currently seen in Europe, North America, Australia, and parts of Asia [27]. In addition, the highly developed cancer service at the KCCC is easily accessible to all in this materially affluent city - state, and is provided free - of - charge to all Kuwaiti nationals. Since met needs for care have been known to be associated with QOL $[28,29]$, one wonders whether these favorable social/institutional care factors could contribute to make the HRQOL of Kuwait women to be comparable to the international data, despite the unfavorable factors (e.g., pathobiological features mentioned above, and use of chemotherapy). In Kuwait, breast cancer is the most common malignancy among women, accounting for $30.3 \%$ of all cancer types, and death occurs in approximately $43 \%$ of patients [27].

\section{Objectives}

The objectives of the study were as follows: First, to highlight the HRQOL scale scores for Kuwaiti women in stable clinical condition with breast cancer, in comparison with the international data. Second, to examine the association of HRQOL with socio-demographic characteristics, stage of disease, type of treatment received in the past (i.e., surgery and radiotherapy), and duration since last treatment (for chemotherapy, surgery and radiotherapy). Third, to assess the variables that predict the global health status/ QOL scale (GQOL) and the five functional scales of the QLQ - C30 (i.e., physical, role, emotional, cognitive, and social functioning), in comparison with the international data. In particular, we examined the relationship between GQOL, the five functional scales and the symptom scales/ items [10]. 
Based on the literature, we hypothesized that despite unfavorable biological/treatment factors (i.e., their relatively younger age, more aggressive tumor and the fact that most were on chemotherapy at the time of assessment) [12-16], Kuwaiti women would have comparable HRQOL scores with the international data because of favorable social/care factors $[28,29]$. Second, there is significant association between HRQOL scale scores and other demographic variables, stage of disease, time since last treatment, and previous surgery and radiotherapy. Third, as indicated by data from other Islamic countries [10], physical and social functioning would be less important in predicting the GQOL. On the other hand, since the occurrence of physical symptoms can cause a change in QOL [30] the symptom scales will be prominent predictors of GQOL.

\section{Methods}

\section{Subjects and setting of the study}

The subjects were consecutive attendees at the outpatient clinic of the medical oncology department of the KCCC who fulfilled the study's inclusion criteria. They were attending follow-up clinic appointment for chemotherapy. No restrictions were made with regard to age and type of chemotherapy [18]. In order to make our findings comparable with those of others, participants were in stable clinical condition (i.e., were not in acute pain, could move about unassisted, did not require hospitalization), had clear consciousness, could easily follow the interview process, and could independently give consent to participate in the study [31]. In this culture, female patients are, as a rule, accompanied to hospital by family members who live with them [32]. Consent was also obtained from the family members; but the patients were interviewed privately in one of the clinic rooms designated for the study. Patients involved in this study were Kuwaiti nationals.

The KCCC is the national center for treatment of cancer, and houses the National Cancer Registry, the Kuwait National Cancer Control Program (in collaboration with the WHO), the Radiation Oncology and Nuclear Medicine Departments, as well as the Medical, Pediatric, and Surgical Oncology Departments, and diagnostic facilities. All cancer cases in the country are referred there. It is an ultra-modern facility, with adequate facilities for diagnosis and treatment of cancer. It has a large complement of specialists in the various fields of oncology. There are daily outpatient clinics and 190 inpatient beds. All services are rendered free - of - charge to Kuwaitis, while others pay nominal fees.

Since this study was not a drug trial, we included patients with all types of treatment, as determined by their doctors. Hence, patients received a wide variety of chemotherapy.

\section{The EORTC QLQ - C30 and BR - 23}

The EORTC QLQ - C30 is a 30 - item generic HRQOL instrument designed to assess cancer patients' physical, psychological and social functioning $[17,31]$. It is composed of nine multi-item scales: 5 functional scales (listed above), a global QOL scale (GQOL), and three symptom scales (fatigue, pain, nausea \& vomiting). In addition, there are five single item symptom scales (dyspnea, sleep disturbance, appetite loss, constipation, \& diarrhea); and a final item evaluates the perceived financial impact of the disease. In the version used for this study (version 3), the first 28 items are rated on a response scale of "not at all (1), to "very much" (4). The time frame is the present moment. For items 29 (on overall general health) and 30 (on overall QOL), the response options range from "very poor" (1) to "excellent" (7), and the time frame is "during the past week".

The 23 - item breast cancer -specific module, the QLQ -BR -23 [18], consists of two multi-item functional scales (body image and sexual functioning), three symptom scales (systemic side effects, breast symptoms, \& arm symptoms), and three single item scales on sexual enjoyment, future perspectives, and upset by hair loss. The response options are "not at all" (1), to "very much" (4), and the time frame is "during the past week", except for the sexual items ("during the past four weeks"). The scoring algorithm recommended by the EORTC [33], was used to transform the responses to values on a scale of 0 $100 \%$. For the functional scales and GQOL, a higher score corresponds to better functioning and QOL. For symptom scales, a higher score corresponds to more frequent and/ or more intense symptoms. A problematic group is defined as one with a GQOL or functional scale score of 33 or less, and a symptom scale score of 66 or more on the QLQ - C30 and QLQ - BR-23 [20,28].

We assessed the internal consistency of the questionnaires by estimating the Cronbach's alpha values of the multiitem scales, based on the recommendation of $>0.70$. The alpha coefficients were highly significant: for the first 28 items of the QLQ - C30, it was 0.94 (split half reliability $=0.84$ ). For the 23 items of the BR-23, the alpha coefficient was $0.92($ split -half reliability $=0.81)$.

\section{Data collection procedure}

At the preliminary stage of the study, the EORTC Quality of Life Unit in Belgium, kindly sent us the questionnaires (English \& Arabic translations) and the scoring manual.

The study was carried out in compliance with the Helsinki Declaration. Hence, ethical approval for the work was obtained from the institutional review panel of the KCCC. In addition, patients and their family caregivers gave verbal informed consent to participate in the study. They 
were duly informed that there would be no negative consequences for declining to participate. As is well known in our culture for such non-invasive studies [32], all families approached freely consented to participate in the study, especially as the approach was made by clinic staff in charge of the cases.

All assessments were based on private interviews by a trained female Arab research assistant, who has had previous experience in administering QOL questionnaires. The research assistant read out the questions to the participants and rated their responses. The criteria for staging disease by the doctors were those of the American Joint Committee on Cancer [34].

\section{Data analysis}

Data were analyzed by the Statistical Package for Social Sciences, version 15 for windows (SPSS Inc., Chicago, Illinois). The scale scores of the QLQ - C30 and BR-23 were computed as recommended [33]. In order to test the first hypothesis, we used scale scores adjusted for age, occupation, marital status and stage of cancer, to compare our data with similar reports from the neighboring United Arab Emirates (UAE), various European countries, and Asia. These reports were located by a limited Medline search for recent English language papers that concerned patients in stable condition from various regions of the world, using the key words: EORTC QLQ - C30; breast cancer. Comparisons were done by effect size calculations and by adopting the operational definition of a clinically meaningful (significant) difference of $10 \%$ between groups $[5,35]$. Where effect size calculations were done for HRQOL scales, we defined a clinically significant difference as $\geq 0.5$ [36]. For the functional scales and the GQOL, we defined subjects with problematic functioning as those who scored $\leq 33 \%$, while subjects in good condition scored $>66 \%$. For symptom scales, subjects scoring $\leq$ $33 \%$ were judged as having less severe symptoms, while those scoring $>66 \%$ had more intense symptoms [20]. We have used the $\leq 33 \%$ cut-off scale score to categorize the patients because that score was suggested from an empirical general population study [37], rather than theoretical speculation. For the second hypothesis, we analyzed the association of scale scores with sociodemographic and clinical variables, by Pearson's correlations, t-tests and one-way ANOVA. The strength of these relationships was tested in multivariate analysis by analysis of covariance (ANCOVA). For the third hypothesis, we used multiple (stepwise) regression analyses to assess the predictors of the functional scales and GQOL scale of the QLQ - C30. With each of the functional scales as dependent variable, the independent (predictor) variables were entered in blocks, starting from the background sociodemographic and clinical variables, followed by the other functional scales, then the symptom scales, and finally, the single item scales of the QLQ - C30. In the case of the GQOL, the scales of the BR-23 were also entered as independent variables. Missing data were handled by deleting cases, analysis- by- analysis. Where there was multiple testing, we used a Bonferroni correction of $\mathrm{P}<0.01$. Otherwise, the level of significance was set at $\mathrm{P}<0.05$, and all tests were two-tailed.

\section{Results}

Socio-demographic and clinical characteristics (Table I)

Over a period of one year (2007/2008), 348 women fulfilled the study's inclusion criteria and freely agreed to participate. They were aged $20-81$ years (mean, 48.3, SD 10.3 ; median $\&$ mode $=46)$. Only six subjects $(1.7 \%$ of $345)$ were aged $<30$ years, while $82(23.8 \%)$ were aged > 55 years. This age pattern is much similar to breast cancer

Table I: Socio - demographic and clinical characteristics of breast cancer patients

\begin{tabular}{|c|c|}
\hline Variables & No. of subjects (\%) \\
\hline \multicolumn{2}{|l|}{ Age groups (yrs): $N=345$} \\
\hline $20-39$ & $60(17.4)$ \\
\hline $40-59$ & $232(67.2)$ \\
\hline $60-81$ & $53(15.4)$ \\
\hline \multicolumn{2}{|c|}{ Mean (SD): 48.3 (I0.3); Median, \& Mode $=46.0$} \\
\hline \multicolumn{2}{|l|}{ Marital status: $\mathrm{N}=347$} \\
\hline Married & $312(89.9)$ \\
\hline Single & $11(3.2)$ \\
\hline Divorced/widow & $24(6.9)$ \\
\hline \multicolumn{2}{|l|}{ Occupational status: $\mathrm{N}=343$} \\
\hline Housewife/retired & $75(21.9)$ \\
\hline Low skill work (e.g., clerk) & $45(13.1)$ \\
\hline Medium skill (e.g., school teacher) & $191(55.7)$ \\
\hline High skill work (e.g., doctor, lawyer, engineer) & $32(9.3)$ \\
\hline \multicolumn{2}{|l|}{ Stage of cancer $(N=344)$} \\
\hline I & $24(7.0)$ \\
\hline II & $118(34.3)$ \\
\hline III & $124(36.0)$ \\
\hline IV & $78(22.7)$ \\
\hline \multicolumn{2}{|l|}{ Type of treatment received } \\
\hline Chemotherapy & $342(98.3)$ \\
\hline Radiotherapy & $73(21.0)$ \\
\hline Surgery & $204(58.6)$ \\
\hline \multicolumn{2}{|l|}{ Duration since last chemotherapy $(N=34 I)$} \\
\hline Past month & $315(92.4)$ \\
\hline I month to 3 months & $13(3.8)$ \\
\hline$>3$ months & $13(3.8)$ \\
\hline \multicolumn{2}{|l|}{ Duration since last radiotherapy: $N=69$} \\
\hline Past month & $48(70.7)$ \\
\hline $1-6$ months & $4(5.7)$ \\
\hline$>6$ months & $17(24.6)$ \\
\hline \multicolumn{2}{|l|}{ Duration since last surgery: $N=202$} \\
\hline Past month & $49(24.3)$ \\
\hline $1-3$ months & $78(38.6)$ \\
\hline$>3$ months & $75(37.1)$ \\
\hline
\end{tabular}

Those with stage IV disease were older (5I.0) than those with other stages. This reached significance in comparison with stage III patients (46.9), $(F=2.7, d f=3 / 34 I, P<0.05)$. 
clinic samples in previous reports from Kuwait $[27,38]$. The participants were predominantly married $(89.9 \%)$, and in full employment (78.1\%). Majority (58.7) were being treated for advanced disease (i.e., stages III \& IV). Apart from chemotherapy, majority $(58.6 \%)$ had had surgery, while $21 \%$ had received radiotherapy. Most (92.4\%) had received a course of chemotherapy in the past month.

\section{Profile of HRQOL scale scores (Tables 2 and 3)}

Of the QLQ - C30 scales, the patients seemed to perform poorly to averagely on both the symptom scales and the functional health status scales. Hence, of the functional scales, the mean score for the global QOL scale (GQOL) was less than $50 \%$, while the range of mean scores for the five scales was $52.6 \%$ to $61.2 \%$, indicating predominantly low level of general wellbeing with average level of functional health status. Judging by the cut-off score of $66 \%$, the best domains of functioning were "cognitive" and "social", where just over one-half of participants had good level of functioning. The domains with poorest functioning were general wellbeing and physical functioning, where only $10.9 \%-25.2 \%$ had good level of functioning.
It is noteworthy that only $6.5 \%$ to $11.2 \%$ had scores that met operational criterion for problematic functioning in the functional domains.

They performed much worse on the symptom scales, because $13.6 \%$ to $40.0 \%$ met the operational criterion for significantly high levels of symptoms. The commonest problem areas (i.e., over one- quarter had "problematic" scores) were, pain, dyspnoea, sleep disturbance and poor appetite. However, $18.3 \%$ to $54.8 \%$ met the operational criterion for "good" functioning for the symptom scales. The patients performed best on the functional scales of the breast specific scales (BR-23) because most (47.8 $70.1 \%$ ) met the operational criterion for "good" functioning. In particular, about two-thirds had good sexual functioning and were optimistic about their future health, while almost one-half expressed little or no problems with their body image.

Of the BR-23 symptom scales, the commonest area with significantly intense level of symptom experience was hair loss. However, $17.2 \%-42.3 \%$ seemed to be relatively free

Table 2: QLQ - C30 \& BR -23 unadjusted scale scores, percentage of subjects with problems \& in good condition ${ }^{\mathrm{a}}$.

\begin{tabular}{|c|c|c|c|c|c|c|}
\hline Variables & $\mathrm{N}$ & $\begin{array}{l}\text { No. of } \\
\text { items }\end{array}$ & Mean (SD) & $95 \%$ C.I. & $\%$ scoring $<33.3 \% c$ & $\%$ scoring $\geq 66.7 \% c$ \\
\hline \multicolumn{7}{|l|}{ C-30 Functional scales ${ }^{b}$} \\
\hline Global QOL/general health & 340 & 2 & $45.3(15.3)$ & $43.7-46.9$ & 6.2 & 10.9 \\
\hline Physical functioning & 330 & 5 & $52.6(18.8)$ & $50.6-54.6$ & 11.2 & 25.2 \\
\hline Role functioning & 340 & 2 & $55.1(21.4)$ & $52.7-57.5$ & 7.6 & 39.1 \\
\hline Emotional & 323 & 2 & $60.3(22.5)$ & $57.7-62.9$ & 8.4 & 45.2 \\
\hline Cognitive & 342 & 4 & $59.9(23.9)$ & $57.3-62.5$ & 5.8 & 51.2 \\
\hline Social & 339 & 2 & $61.2(22.7)$ & $58.8-63.6$ & 6.5 & 52.8 \\
\hline \multicolumn{7}{|l|}{ C - 30 symptoms/scales ${ }^{c}$} \\
\hline Fatigue & 331 & 3 & $38.9(21.3)$ & $36.5-41.3$ & 29.0 & 13.6 \\
\hline Nausea \& vomiting & 334 & 2 & $30.2(24.5)$ & $27.6-32.8$ & 48.5 & 12.0 \\
\hline Pain & 334 & 2 & $43.8(21.7)$ & $41.4-46.2$ & 20.1 & 27.5 \\
\hline Dyspnoea & 335 & 1 & $42.4(27.8)$ & $39.4-45.4$ & 18.8 & 40.0 \\
\hline Sleep disturbance & 338 & 1 & $42.7(28.2)$ & $39.7-45.7$ & 18.3 & 39.3 \\
\hline Appetite loss & 339 & 1 & $37.5(28.0)$ & $34.5-40.5$ & 25.1 & 32.7 \\
\hline Constipation & 345 & I & $27.8(28.2)$ & $24.8-30.8$ & 42.0 & 22.0 \\
\hline Diarrhea & 343 & 1 & $22.1(27.5)$ & $19.1-25.1$ & 54.8 & 19.2 \\
\hline Financial impact & 344 & 1 & $31.2(25.2)$ & $28.4-34.0$ & 29.1 & 19.8 \\
\hline \multicolumn{7}{|c|}{ QOL - BR23: Functional scales ${ }^{b}$} \\
\hline Body image & 299 & 4 & $61.8(23.3)$ & $59.0-64.6$ & 7.0 & 47.8 \\
\hline Sexual functioning & 303 & 2 & $69.9(23.6)$ & $67.1-72.7$ & 1.3 & 68.0 \\
\hline Sexual enjoyment & 221 & I & $61.5(23.0)$ & $58.3-64.7$ & 2.3 & 70.1 \\
\hline Future perspective & 334 & 1 & $59.5(31.9)$ & $56.1-62.9$ & 11.7 & 64.7 \\
\hline \multicolumn{7}{|l|}{ BR23: Symptom scales ${ }^{c}$} \\
\hline Systemic side effects & 300 & 7 & $40.1(17.5)$ & $38.1-42.1$ & 29.3 & 6.7 \\
\hline Breast symptoms & 293 & 4 & $35.6(25.4)$ & $32.6-38.6$ & 42.3 & 14.3 \\
\hline Arm symptoms & 318 & 3 & $38.2(23.4)$ & $35.6-40.8$ & 33.0 & 13.8 \\
\hline Upset by hair loss & 331 & 1 & $44.8(29.6)$ & $41.6-48.0$ & 17.2 & 40.8 \\
\hline
\end{tabular}

aFor functional scales, subjects scoring $<33.3 \%$ have problems; those scoring $\geq 66.7 \%$ have good functioning. For symptom scales/symptoms, subjects scoring $<33.3 \%$ have good functioning; those scoring $=66.7 \%$ have problems

$\mathrm{b}$ For functional scales, higher scores indicate better functioning

c For symptom scales, higher scores indicate worse functioning 
Table 3: QLQ - C30 \& BR - 23 adjusted scale scores*

\begin{tabular}{|c|c|c|c|}
\hline Variables & $\mathrm{N}$ & Mean (SE) & $95 \%$ C.I. \\
\hline \multicolumn{4}{|l|}{ QLQ C-30 functional scales } \\
\hline Global QOL/general health & 331 & $45.0(0.8)$ & $43.4-46.7$ \\
\hline Physical functioning & 316 & $52.7(1.1)$ & $50.6-54.8$ \\
\hline Role functioning & 331 & $55.1(1.2)$ & $52.7-57.4$ \\
\hline Emotional & 314 & $60.2(1.8)$ & $57.7-62.7$ \\
\hline Cognitive & 333 & $59.4(1.3)$ & $57.3-62.5$ \\
\hline Social & 330 & $61.3(1.3)$ & $58.9-63.8$ \\
\hline \multicolumn{4}{|l|}{ QLQ C - 30 symptoms scales } \\
\hline Fatigue & 322 & $38.9(1.2)$ & $36.5-41.2$ \\
\hline Nausea \& vomiting & 326 & $30.2(1.3)$ & $27.5-32.8$ \\
\hline Pain & 325 & $43.8(1.2)$ & $41.4-46.2$ \\
\hline Dyspnoea & 327 & $42.1(1.5)$ & $39.1-45.1$ \\
\hline Sleep disturbance & 329 & $42.7(1.6)$ & $39.5-45.6$ \\
\hline Appetite loss & 330 & $37.4(1.5)$ & $34.4-40.4$ \\
\hline Constipation & 336 & $27.8(1.5)$ & $24.8-30.8$ \\
\hline Diarrhea & 334 & $21.9(1.5)$ & $19.0-24.9$ \\
\hline Financial impact & 335 & $31.2(1.4)$ & $28.5-33.9$ \\
\hline \multicolumn{4}{|l|}{ QOL - BR23: functional scales } \\
\hline Body image & 290 & $61.8(1.4)$ & $59.2-64.5$ \\
\hline Sexual functioning & 295 & $70.2(1.3)$ & $67.6-72.9$ \\
\hline Sexual enjoyment & 215 & $61.8(1.6)$ & $58.7-64.9$ \\
\hline Future perspective & 325 & $59.7(1.8)$ & $56.3-63.1$ \\
\hline \multicolumn{4}{|l|}{ QLQ - BR23: Symptom scales } \\
\hline Systemic side effects & 292 & $40.2(1.0)$ & $38.2-42.2$ \\
\hline Breast symptoms & 284 & $35.3(1.5)$ & $32.4-38.3$ \\
\hline Arm symptoms & 309 & $38.2(1.3)$ & $35.6-40.8$ \\
\hline Upset by hair loss & 323 & $44.4(1.6)$ & $41.2-47.6$ \\
\hline
\end{tabular}

* Scores adjusted for age, stage of cancer, marital status, and occupation

For functional scales, higher scores indicate better functioning

For symptom scales, higher scores indicate worse functioning

from intense levels of symptoms for the breast -specific symptom scales.

\section{Factors associated with HRQOL scale scores}

Using Pearson's correlation analysis, the correlation of age with scale scores was low (i.e., < 0.2). The correlations were significant and positive for the following functional scales: emotional functioning, cognitive functioning, social functioning, sexual enjoyment, body image ( $\mathrm{r}$ ranged from 0.12 to $0.18, \mathrm{P}<0.02$ ), and sexual functioning $(\mathrm{r}=0.21, \mathrm{P}<0.0001)$. The correlations were significant and negative for the following symptom scales: systemic side effects, breast symptoms, arm symptoms, upset by hair loss ( $\mathrm{r}$ ranged from -0.14 to $-0.19, \mathrm{P}<0.01$ ). In other words, for the functional and symptom scales, older patients tended to have better functioning and less intense symptoms than the younger patients.

Using Pearson's correlation analysis for the symptom scales of the QLQ - C30, the correlation with GQOL was highest for fatigue $(\mathrm{r}=0.21, \mathrm{P}<0.0001)$. In one-way ANOVA, marital and occupational status were not significantly associated with scale scores $(P>0.05)$. Subjects with advanced disease tended to have worse functioning.
This reached significance for the following: role functioning (stage IV < stage II, F = 3.8, $\mathrm{df}=3 / 335, \mathrm{P}<0.01$ ), diarrhea (stage $\mathrm{IV}<$ stages $\mathrm{I} \& \mathrm{II}, \mathrm{F}=3.5, \mathrm{df}=3 / 338, \mathrm{P}=$ 0.02 ), and future perspectives (stage III < stages I \& II, F = $3.5, \mathrm{df}=3 / 329, \mathrm{P}=0.02)$. Those who had surgery had significantly less complaints about diarrhea $(\mathrm{t}=2.8, \mathrm{df}=$ $268, \mathrm{P}=0.005)$, but more breast symptoms $(\mathrm{t}=2.1, \mathrm{df}=$ $227, \mathrm{P}<0.04)$.

Those who received radiotherapy had significantly more problems with fatigue $(\mathrm{t}=2.2, \mathrm{df}=185, \mathrm{P}=0.03)$, breast symptoms $(\mathrm{t}=2.1, \mathrm{df}=159, \mathrm{P}=0.04)$, arm symptoms $(\mathrm{t}$ $=2.3, \mathrm{df}=175, \mathrm{P}=0.02)$, and future perspectives $(\mathrm{t}=2.3$, $\mathrm{df}=187, \mathrm{P}=0.02)$.

There was no significant consistent trend in the association between scale scores and duration of last treatment for surgery and radiotherapy.

In ANCOVA, with age, stage of cancer, marital status, occupation, and duration since last chemotherapy as covariates, age was a significant covariate for sexual functioning $(\mathrm{F}=5.7, \mathrm{P}<0.02)$; marital status was a significant covariate for sexual enjoyment $(\mathrm{F}=5.5, \mathrm{P}<0.02)$; and time since chemotherapy was a significant covariate for future perspectives $(\mathrm{F}=6.1, \mathrm{P}<0.02)$ and body image $(\mathrm{F}$ = 4.9, $\mathrm{P}<0.03$ ).

\section{Predictors of global QOL and functional scale scores (Table 4)}

In stepwise regression analyses, with the GQOL and functional scales, each, as dependent variables, the following trends emerged: First, the socio-demographic variables that entered the regression equations (i.e., age, occupational status and marital status) played rather marginal roles (i.e., variance 2.2 - 5.2\%) in predicting GQOL, physical functioning and social functioning, respectively. Second, the clinical variables did not enter the equations. Third, the functional scales were more important (i.e., accounted for the highest proportion of variance) than the symptom scales. Fourth, the variables that accounted for the highest proportion of variance for each scale were as follows: (i) for global QOL, social functioning; (ii) for physical functioning, role functioning; (iii) for role functioning, physical functioning; (iv) for emotional functioning, cognitive functioning; ( $v$ ) for cognitive functioning, emotional functioning; and (vi) for social functioning, emotional functioning. Fifth, financial difficulty was a highly significant predictor of global QOL $(\mathrm{P}<0.007)$ and social functioning $(\mathrm{P}<0.001)$.

\section{Discussion \\ Profile of EORTC QLQ - C30 and BR-23 scores}

We assessed 348 predominantly middle aged Arab women who were mostly receiving chemotherapy. The mean scores for QLQ - C30 and BR-23 indicated that the 
Table 4: Predictors of functional health status and global quality of life

\begin{tabular}{|c|c|c|c|c|c|c|}
\hline Dependent variable & $\begin{array}{l}\text { Predictors or independent } \\
\text { variables }\end{array}$ & $\%$ Variance & $\begin{array}{l}\text { Total } \\
\text { vari- } \\
\text { ance }\end{array}$ & $\begin{array}{l}\text { Standardized } \\
\text { Beta }\end{array}$ & $\mathrm{T}$ value & P level \\
\hline \multirow[t]{5}{*}{ Global QOL \& General health } & Social functioning & 11.6 & 29.7 & -0.31 & 3.2 & 0.002 \\
\hline & Sexual enjoyment & 4.5 & & -0.26 & 3.1 & 0.003 \\
\hline & Pain & 4.4 & & -0.33 & 3.5 & 0.001 \\
\hline & Financial difficulty & 4.1 & & 0.24 & 2.8 & 0.007 \\
\hline & Age & 5.2 & & -0.14 & 1.9 & 0.07 \\
\hline \multirow[t]{3}{*}{ Physical functioning } & Occupational status & 2.2 & 53.3 & 0.9 & 1.7 & 0.09 \\
\hline & Role functioning & 45.7 & & 0.51 & 8.0 & 0.0001 \\
\hline & Cognitive functioning & 5.4 & & 0.29 & 4.6 & 0.0001 \\
\hline \multirow[t]{8}{*}{ Role functioning } & Physical functioning & 47.2 & 67.7 & 0.31 & 5.2 & 0.0001 \\
\hline & Cognitive function & 5.5 & & 0.01 & 0.14 & 0.89 \\
\hline & Social function & 1.8 & & 0.07 & 1.2 & 0.22 \\
\hline & Pain & 7.2 & & -0.30 & 4.5 & 0.0001 \\
\hline & Fatigue & 1.8 & & -0.11 & 1.7 & 0.09 \\
\hline & Dyspnoea & 1.9 & & -0.19 & 3.3 & 0.001 \\
\hline & Appetite loss & 1.2 & & -0.15 & 2.9 & 0.004 \\
\hline & Constipation & 1.0 & & 0.13 & 2.3 & 0.02 \\
\hline \multirow[t]{5}{*}{ Emotional functioning } & Cognitive functioning & 59.6 & 67.7 & 0.48 & 7.4 & 0.0001 \\
\hline & Social function & 3.3 & & 0.18 & 3.4 & 0.001 \\
\hline & Pain & 1.8 & & -0.11 & 1.8 & 0.08 \\
\hline & Nausea \& vomiting & 0.08 & & -0.0 .5 & 0.8 & 0.42 \\
\hline & Constipation & 0.02 & & -0.19 & 3.6 & 0.0001 \\
\hline \multirow[t]{5}{*}{ Cognitive functioning } & Emotional functioning & 59.6 & 69.4 & 0.47 & 7.6 & 0.0001 \\
\hline & Physical function & 6.7 & & 0.21 & 3.9 & 0.0001 \\
\hline & Social function & 1.2 & & 0.12 & 2.2 & 0.03 \\
\hline & Nausea \& vomiting & 1.2 & & -0.11 & 2.1 & 0.04 \\
\hline & Pain & 0.7 & & -0.13 & 2.1 & 0.04 \\
\hline \multirow[t]{5}{*}{ Social functioning } & Marital status & 2.2 & 47.3 & -0.11 & 2.0 & 0.05 \\
\hline & Emotional functioning & 35.1 & & 3.5 & 5.1 & 0.0001 \\
\hline & Role function & 4.4 & & 0.11 & 1.5 & 0.14 \\
\hline & Fatigue & 2.3 & & -0.19 & 2.8 & 0.006 \\
\hline & Finance difficulty & 3.4 & & -0.21 & 3.4 & 0.001 \\
\hline
\end{tabular}

patients had poor to average functioning and intense symptom experience. We shall now examine the significance of these findings in the context of the international data.

The literature on EORTC QLQ has emphasized that comparison of data should go beyond the usual presentation of mean scores and significant differences $[4,35,39,40]$. Towards this end, Table 2 shows that, although the mean scores for QLQ - C30 indicated that the patients had poor to average scale scores, only $5.8 \%$ to $11.2 \%$ had scores that met the $\leq 33 \%$ criterion for problematic functioning, while $12.0 \%$ to $40.0 \%$ met the $>66 \%$ criterion for more severe symptoms. In other words, despite the reality and popular perception of cancer as a killer disease, many patients undergoing effective modern treatment can expect to have tolerable levels of physical, psychological and social functioning and subjective wellbeing [41-43]. This was particularly the case for the functional scales of the BR-23, where majority of subjects had scores indicating good functioning. It is interesting that, despite their condition, about one-third were hopeful about the future. These findings constitute an evidence base for the country's cancer control program, to boost national health education about prognosis in cancer [8].

With regard to the pattern of functional scale scores of the QLQ - C30, the pattern of responses of our patients was similar to the international data for moderately extensive/ severe disease, because the lowest scores were noted for physical functioning and role functioning, while the highest scores were for cognitive and social functioning [44]. This is in line with the reality of a severely debilitating physical illness, where the much available family social support and institutional support can help to boost psychosocial wellbeing [28].

\section{Factors associated with HRQOL}

Of the factors investigated, the noteworthy associations with HRQOL in univariate analyses were age, stage of cancer, receipt of radiotherapy and fatigue. Although the correlations of age with scale scores were rather low, the 
results are in line with the international data in showing that younger women with cancer tend to have poorer functioning and more intense symptoms, especially if they are on chemotherapy [12-16]. It has been suggested that younger patients are more likely to suffer adverse effects because of induction of early menopause and possible infertility [12]. While the finding of association of disease stage with HRQOL scale scores indicates that the questionnaire has known groups validity, the significant associations were only for three scales (role functioning, diarrhea and future perspective). In the studies that found no significant association between QOL and cancer stage at diagnosis, it has been suggested that the diagnosis of breast cancer is so stressful that it may result in a pattern of psychological morbidity for women in early stages that is similar to that experienced by women with more advanced disease [15]. Coupled with the indication that future perspectives and body image perceptions were better for those who had last treatment over a month ago, $[12,45]$, the above findings should be an evidence base for the contents of a cancer counseling clinic for our patients.

\section{Predictors of HRQOL}

The highlight of our regression analyses is that, contrary to the third hypothesis[30], the functional scale scores were more important in predicting functional scales, than the scores of the symptom scales, while social functioning accounted for the highest proportion of variance in GQOL. This is in line with a Canadian report, which indicated that social functioning was strongly correlated with global QOL, while physical and role functioning were highly correlated [46]. This result has been explained from the perspective of the phenomenon of response shift [45], which occurs if the patient's perception of the severity of the symptoms changes over time. It is suggested that many patients gradually adapt to the situation following diagnosis and treatment, becoming better at coping with symptoms, such that the patients no longer perceive the burden of the symptoms to be as great as the first time [45]. Hence, for such patients, the physical, emotional and social limitations of the illness tend to become more important determinants of QOL rather than the physical symptoms. However, in a German study that assessed the role of the symptom scales in predicting HRQOL, it was found that fatigue was the most important predictor of QOL [47]. While pain was the only symptom scale that entered our regression model for GQOL, we note that, in univariate analysis, fatigue had the highest correlation with GQOL, of the symptom scales of the QLQ-C30; and fatigue was a significant predictor for social functioning $(2.3 \%$ variance, $\mathrm{P}<0.006)$. Hence, clinicians should pay particular attention to how to alleviate fatigue, in addition to the usual emphasis on pain [47].

The predictive power of financial difficulty shows that, despite institutional supports, cancer is associated with significant family financial burden. It appears that, although treatment was provided free -of -charge, families still made significant out -of -pocket expenses.

Comparison with the international data (additional file I) The relative youth of our subjects, in comparison with the international data, is noteworthy. The life expectancy at birth for Kuwaiti women is 78.95 years (2009 estimate: https://www.cia.gov/library/publications/the-worldfactbook/geos/KU.html). The following pattern emerged in comparing our scale scores with those of the international EORTC QLQ data (additional file 1) [48,49], as well as previous Kuwaiti QOL data from a general population study [50] and women with multiple sclerosis [32], using the global QOL scale of the 26-item WHOQOL-Bref. First, for the functional scales of the QLQ - C30, the Kuwaiti global QOL score was less than those of other countries by at least $10 \%$. In particular, the GQOL score from the neighboring UAE was $20 \%$ higher, while that for three Islamic countries was $14 \%$ higher. The pattern was the same for physical and role functioning, except role functioning data from China [24]. For emotional functioning, Kuwaiti scores were at least $10 \%$ less than the data from Korea, Sweden, and other Western nations. The tendency for the emotional functioning data from the UAE and three Islamic countries to be higher than that from Kuwait, did not reach significance (Effect size: 0.22, 95\% C.I. $=-0.02-0.46)$. For cognitive and social functioning, Kuwaiti scores were at least $10 \%$ less than the data from the UAE, the three Islamic countries and the Western nations.

Second, for the symptom scales of the QLQ - C30, the Kuwaiti data indicated more intense symptoms for dyspnoea, appetite and diarrhea and more financial difficulty (i.e., at least $10 \%$ difference).

Third, for the functional scales of the BR - 23, our data was at the middle of the range of the international data for body image, being much similar to the data from Iran and China, indicating better functioning than the Korean data (over 20\% difference), but worse functioning than most data from the Western world. For sexual functioning, the Kuwaiti data was at the top of the range of the international data, being similar to the Iranian and UAE data, but indicating better functioning for most data from the Western world. Fourth, of the symptom scales of the BR-23, the mean scores indicated that Kuwaiti women had more intense symptoms than women from all the comparison countries for systemic side effects, breast symptoms and arm symptoms. Regarding systemic side effects, Kuwaiti women had at least $10 \%$ difference with women from the Western world, Korea, and Iran, but similar scores with women from the UAE (Effect size, 95\% C.I: 0.09, -0.15 $0.33)$. The pattern was the same for breast symptoms, 
except that the Kuwaiti women had clinically significantly more intense symptoms than the women from the UAE.

Fifth, using the $0-100 \%$ scale of the WHOQOLBref[32,50], Kuwaiti women in the general population, women in the general population who rated themselves as being sick, and women attending clinic for multiple sclerosis, all had significantly higher global QOL scores than the women with breast cancer (Effect size, 95\% C.I: $1.22,1.10-1.35$; and $0.83,0.60-1.05$, respectively. Comparison Kuwaiti data were adjusted for socio-demographic variables).

In summary, the profile of scale mean scores for QLQ C30 indicated that Kuwaiti women had clinically significantly poorer global QOL and functional scale scores, and more intense symptom experience for most scales, in comparison with the international data, including data from neighboring Islamic countries. For the breast specific scale (BR-23), Kuwaiti women seemed to have clinically significantly better sexual functioning, but more severe treatment side effect symptom experience, especially systemic side effects and breast symptoms. The poor global QOL score of Kuwaiti women with cancer was confirmed by the fact that they had significantly lower scores than their compatriots in the general population and those with multiple sclerosis. It appears, therefore, that the experience of clinically more severe symptoms among Kuwaiti women, as a group, was a significant contributor to their low global QOL and comparatively poorer physical, emotional and social functioning [30]. In view of this, clinicians treating Kuwaiti women for cancer should take particular interest in preparing the patients for the acute toxicities of breast cancer treatment [12]. Other factors that could have contributed to their comparatively poor HRQOL are, their relative youth, the fact that they were on chemotherapy [12-16], and the aggressive histopathologic picture of breast cancer in Kuwait [27]. In other words, the biological and treatment side effect factors seemed to be more important than family and institutional supports in the cross-sectional HRQOL outcome of our patients. A longitudinal study is needed to confirm this trend. However, we note that the laudable institutional supports did not include any program on psycho-oncology. Our general experience is that women with breast cancer do not receive any formal psycho-education on the nature of the illness, the implications of treatment and how to cope with cancer. Our findings, therefore, call for a formal program of psycho-oncology at the KCCC, to counsel patients on the nature of the disease and treatment side effects, address their psychosocial concerns and explore methods of coping [51].

\section{Limitations and strengths of the study}

Our findings cannot be generalized to the general population of women with breast cancer because the study was cross-sectional, the participants were a selected clinic population, and there is no general population reference data for the EORTC QLQ - C30 in Kuwait [52]. In addition, we did not sort the patients into categories of disease progression and disease free survivors [28], and the fact that the responses were based on interview could have introduced a bias for patients who may have wished to respond privately. However, we have used an internationally well validated questionnaire to describe the HRQOL of a fairly large number of breast cancer survivors, and we have presented our results in such a way as to make them comparable with data from other countries. Also, there is published data on general population norms for a popular QOL instrument (WHOQOL -BREF) that was presented using the $0-100 \%$ scale (or the percentage scale maximum method - \% SM) [50]. The value of the \%SM measure is that it can be used for making comparison with the scale scores of other questionnaires [53].

Of the Arabic samples reported in the literature $[9,10]$, ours is the largest. Furthermore, we categorized scale scores into those with/without significant problems $[20,28,37]$, and applied the principle of clinically significant difference in scale scores between groups [35] to compare our results with the international data. Hence, we met the need to provide clinically-based benchmarks in interpreting QOL data, so as to make them meaningful to clinicians $[4,5,44]$. Finally, it appears that our patients had similar demographic characteristics with those of breast cancer clinic populations in Kuwait [27,38].

\section{Conclusion}

The relatively high number that met the criterion for good functioning on the physical, role, emotional, cognitive, social, and sexual functioning scales is an evidence base to boost national health education about psychosocial prognosis in cancer. Their sense of optimism in the face of such a devastating disease is particularly noteworthy. However, in view of their poor performance on the symptom scales, clinicians treating Kuwaiti women with breast cancer should take particular interest in preparing the patients for the acute toxicities of treatment, as well as addressing fatigue and pain $[12,47]$. The findings call for the institution of a psycho-oncology service at the KCCC, to address psycho-social outcome.

\section{Competing interests}

The authors declare that they have no competing interests.

\section{Authors' contributions}

SA conceived the study. SA and JUO jointly designed the study, analyzed the data and wrote up the manuscript. SA supervised data collection. Both authors read and approved the manuscript. 


\section{Additional material}

\section{Additional file 1}

Tables five - seven in landscape. The data provided compared the EORTC QLQ - C30 and BR - 23 scores from several countries with our results.

Click here for file

[http://www.biomedcentral.com/content/supplementary/14712407-9-222-S1.doc]

\section{Acknowledgements}

We thank Ms Nashwa Al-Hassan for administering the questionnaires. Ms Deepa Nair entered the data in SPSS. We thank Ms Mona Alach for secretarial assistance and all the nurses and doctors at KCCC for their cooperation. We thank the patients and families for their cooperation.

\section{References}

I. Sloan JA, Cella D, Frost MH, Guyatt GH, Sprangers MAG, Symonds MAG: Assessing clinical significance in measuring oncology patient quality of life: introduction to the symposium, content overview, and definition of terms. Mayo Clin Proc 2002, 77:367-370.

2. Steeg AFW van der, De Vries J, Roukema JA: Quality of life and health status in breast carcinoma. Eur J Sur Oncol 2004, 30:105I-1057.

3. Montazeri A: Health-related quality of life in breast cancer patients: a bibliographic review of the literature from 1974 to 2007. J Expt Clin Cancer Res 2008, 27:32.

4. King MT, Fayers PM: Making quality-of-life results more meaningful for clinicians. Lancet 2008, 37 I(96 14):709-7I0.

5. Sloan JA, Frost MH, Berzon R, Dueck A, Guyatt G, Moinpour C, Sprangers M, Ferrans C, Cella D: Clinical Significance Consensus Meeting Group. The clinical significance of quality of life assessments in oncology: a summary for clinicians. Support Care Cancer 2006, I 4:988-998.

6. Albert US, Koller M, Lorenz W, Kopp I, Heitmann C, Stinner B, Rothmund M, Schulz KD, Quality Circle: Quality of life profile: from measurement to clinical application. Breast 2002, I I:324-334.

7. Sprangers MA: Quality-of-life assessment in oncology. Achievements and challenges. Acta Oncol 2002, 41:229-237.

8. Awadalla AW, Ohaeri JU, Gholoum A, Khalid AO, Hamad AM, Jacob $A$ : Factors associated with quality of life of outpatients with breast cancer and gynecologic cancers and their family caregivers: a controlled study. BMC Cancer 2007, 7:102.

9. Awad MA, Denic S, El Taji K: Validation of the European Organization for Research and Treatment in Cancer Quality of Life Questionnaire for Arabic - speaking populations. Ann NY Acad Sci 2008, I 138:146-154.

10. Scott NW, Fayers PM, Aaronson NK, Bottomley A, de Graeff A, Groenvold M, Koller M, Petersen MA, Sprangers MA, EORTC Quality of Life Group; Quality of Life Cross-Cultural Meta-Analysis Group: Collaborators: The relationship between overall quality of life and its subdimensions was influenced by culture: analysis of an international database. J Clin Epidemiol 2008, 61:788-795.

II. Diener E: Subjective well-being: The science of happiness and a proposal for a national index. Am Psychologist 2000, 55:34-43.

12. Hopwood P, Haviland J, Mills J, Sumo G, M Bliss J, START Trial Management Group: The impact of age and clinical factors on quality of life in early breast cancer: an analysis of 2208 women recruited to the UK START Trial (Standardisation of Breast Radiotherapy Trial). Breast 2007, 16:24I-25I.

13. Parmar V, Badwe RA, Hawaldar R, Rayabhattanavar S, Varghese A, Sharma R, Mittra I: Validation of EORTC quality-of-life questionnaire in Indian women with operable breast cancer. Natl Med J India 2005, I 8: I72-I77.

14. Schou I, Ekeberg $\varnothing$, Sandvik L, Hjermstad MJ, Ruland CM: Multiple predictors of health-related quality of life in early stage breast cancer. Data from a year follow-up study compared with the general population. Qual Life Res 2005, I 4:1813-1823.

15. Janz NK, Mujahid M, Lantz PM, Fagerlin A, Salem B, Morrow M, Deapen D, Katz SJ: Population-based study of the relationship of treatment and sociodemographics on quality of life for early stage breast cancer. Qual Life Res 2005, | 4: | 1467-| 479.

16. Wenzel LB, Fairclough DL, Brady MJ, Cella D, Garrett KM, Kluhsman BC, Crane LA, Marcus AC: Age-related differences in the quality of life of breast carcinoma patients after treatment. Cancer 1999, 86: I768-1774.

17. Aaronson NK, Ahmedzai S, Bergman B, Bullinger M, Cull A, Duez NJ, Filiberti A, Flechtner H, Fleishman SB, de Haes JC, Kaasa S, Klee M, Osoba D, Razavi D, Rofe PB, Schraub S, Sneeuw K, Sullivan M, Takeda F: The European Organization for Research and Treatment of Cancer QLQ-C30: a quality-of-life instrument for use in international clinical trials in oncology. J Natl Cancer Inst 1993, 85:365-376.

18. Sprangers MA, Groenvold M, Arraras JI, Franklin J, te Velde A, Muller M, Franzini L, Williams A, de Haes HC, Hopwood P, Cull A, Aaronson NK: The European Organization for Research and Treatment of Cancer breast cancer-specific quality-of-life questionnaire module: first results from a three-country field study. I Clin Oncol 1996, 14:2756-2768.

19. Montazeri A, Harirchi I, Vahdani M, Khaleghi F, Jarvandi S, Ebrahimi M, Haji-Mahmoodi M: The EORTC breast cancer-specific quality of life questionnaire (EORTC QLQ-BR23): translation and validation study of the Iranian version. Qual Life Res 2000, 9:177-184.

20. Ahn SH, Park BW, Noh DY, Nam SJ, Lee ES, Lee MK, Kim SH, Lee KM, Park SM, Yun YH: Health -related quality of life in disease -free survivors of breast cancer with the general population. Ann Oncol 2007, 18:173-182.

21. Sprangers MA, Tempelaar R, Heuvel WJ van den, de Haes HC: Explaining quality of life with crisis theory. Psychooncology 2002, I I:419-426.

22. Guzelant A, Goksel T, Ozkok S, Tasbakan S, Aysan T, Bottomley A: The European Organization for Research and Treatment of Cancer QLQ-C30: an examination into the cultural validity and reliability of the Turkish version of the EORTC QLQC30. Eur J Cancer Care (Engl) 2004, I 3: I35- I 44.

23. Okamoto T, Shimozuma K, Katsumata N, Koike M, Hisashige A, Tanaka K, Ohsumi S, Saito M, Shikama N, Mitsumori M, Yamauchi C, Watanabe T: Task Force of the Japanese Breast Cancer Society for 'The Development of Guidelines for Quality of Life Assessment Studies of Breast Cancer Patients' Measuring quality of life in patients with breast cancer: a systematic review of reliable and valid instruments available in Japan. Breast Cancer 2003, 1 0:204-213.

24. Wan C, Meng Q, Yang Z, Tu X, Feng C, Tang X, Zhang C: Validation of the simplified Chinese version of EORTC QLQ-C30 from the measurements of five types of inpatients with cancer. Ann Oncol 2008, 19:2053-2060.

25. Yun YH, Bae SH, Kang IO, Shin KH, Lee R, Kwon SI, Park YS, Lee ES: Cross-cultural application of the Korean version of the European Organization for Research and Treatment of Cancer (EORTC) Breast-Cancer-Specific Quality of Life Questionnaire (EORTC QLQ-BR23). Support Care Cancer 2004, I 2:44|-445.

26. Jaiyesimi AO, Sofela EA, Rufai AA: Health related quality of life and its determinants in Nigerian breast cancer patients. Afr J Med Med Sci 2007, 36:259-265.

27. Saleh F, Abdeen S: Pathobiological features of breast tumours in the State of Kuwait: a comprehensive analysis. J Carcinogenesis 2007, 6: 12

28. Waldman A, Pritkuleit $R$, Raspe $H$, Katalinic A, The OVIS study: Health - related quality of life measured by the EORTC QLQ - C30 and BR-23 in German female patients with breast cancer from Schleswig -Holstein. Qual Life Res 2007, 16:767-776.

29. Slade M, Leese M, Ruggeri M, Kuipers E, Tansella M, Thornicroft G: Does meeting needs improve quality of life? Psychother Psychosom 2004, 73: 183-189.

30. Boehmer S, Luszczynska A: Two kinds of items in quality of life instruments: 'indicator and causal variables' in the EORTC QLQ - C30. Qual Life Res 2006, 15:131-141.

31. Kaasa S, Bjordal K, Aaronson N, Moum T, Wist E, Hagen S, Kvikstad $A$ : The EORTC core quality of life questionnaire (QLQ-C30): 
validity and reliability when analysed with patients treated with palliative radiotherapy. Eur J Cancer 1995, 3 IA:|3-|4.

32. Alshubaili AF, Awadalla AW, Ohaeri JU, Mabrouk AA: Relationship of depression and disability with the quality of persons with multiple sclerosis. BMC Neurol 2007, 7:3I.

33. Fayers PM, Aaronson NK, Bjordal K, Groenvold M, Curran D, Bottomley A, on behalf of the EORTC Quality of Life Group: The EORTC QLQ - C30 Scoring Manual 3rd edition. Brussels: European Organization for Research and Treatment of Cancer; 200I.

34. Greene FL, Page DL, Fleming ID: AJCC cancer staging manual 6th edition. New York: Springer; 2002.

35. Osoba D, Rodrigues G, Myles J, Zee B, Pater J: Interpreting the significance of changes in health-related quality-of-life scores. $J$ Clin Oncol 1998, 16:139-144.

36. Norman GR, Sloan JA, Wyrwich KW: Interpretation of changes in health-related quality of life: the remarkable universality of half a standard deviation. Med Care 2003, 41:582-592.

37. Fayers PM: Interpreting quality of life data: population- based reference data for the EORTC QLQ - C30. Eur J Cancer 200I, 37:| $33|-| 334$.

38. Abuzallouf S, Motawy M, Thotathil Z: Baseline staging of newly diagnosed breast cancer - Kuwait Cancer Control Center experience. Med Prin Pract 2007, 16:22-24.

39. Guyatt GH, Osoba D, Wu AW, Wyrwich KW, Norman GR, Clinica Significance Consensus Meeting Group: Methods to explain the clinical significance of health status measures. Mayo Clinic Proc 2002, 77:37I-383.

40. Cocks K, King MT, Velikova G, Fayers PM, Brown JM: Quality, interpretation and presentation of European Organisation for Research and Treatment of Cancer quality of life questionnaire core $\mathbf{3 0}$ data in randomized controlled trials. Eur Cancer 2008, 44: 1793-1798.

4I. Bloom JR, Stewart SL, Chang S, Banks PJ: Then and now: quality of life of young breast cancer survivors. Psychooncology 2004, 13:147-160.

42. Neyt M, Albrecht J: The long -term evolution of quality of life for disease -free breast cancer survivors: a comparative study in Belgium. J Psychosoc Oncol 2006, 24:89-123.

43. Dorval M, Maunsell E, Deschesnes L, Brisson J, Masse B: Long-term quality of life after breast cancer: comparison of 8 -year survivors with population controls. J Clin Oncol 1998, 16:487-494.

44. King MT: The interpretation of scores from the EORTC quality of life questionnaire QLQ-C30. Qual Life Res 1996, 5:555-567.

45. Klee MC, King MT, Machin D, Hansen HH: A clinical model for quality of life assessment in cancer patients receiving chemotherapy. Ann Oncol 2000, I I:23-30.

46. Osoba D, Zee B, Pater J, Warr D, Kaizer L, Latreille J: Psychometric properties and responsiveness of the EORTC quality of Life Questionnaire (QLQ-C30) in patients with breast, ovarian and lung cancer. Qual Life Res 1994, 3:353-364.

47. Arndt V, Stegmaier C, Ziegler H, Brenner H: A population -based study of the impact of specific symptoms on quality of life in women with breast cancer I year after diagnosis. Cancer 2006 107:2496-2503

48. Michelson $\mathrm{H}$, Bolund $\mathrm{C}$, Nilsson B, Brandberg $\mathrm{Y}$ : Health-related quality of life measured by the EORTC QLQ - C30: reference values from a large sample of the Swedish population. Acta Oncol 2000, 39:477-484.

49. Apolone G, Filiberti A, Cifani S, Ruggiata R, Mosconi P: Evaluation of the EORTC QLQ - C30 questionnaire: a comparison with SF-36 Health Survey in a cohort of Italian long-survival cancer patients. Ann Oncol 1998, 9:549-557.

50. Ohaeri JU, Awadalla AW, Gado OM: Subjective quality of life in a nationwide sample of Kuwaiti subjects using the short version of the WHO quality of life instrument. Soc Psychiatry Psychiatri Epidemiol 2008 in press.

5I. Holland J, Weiss T: The new standard of quality cancer care integrating the psychosocial aspects in routine cancer from diagnosis through survivorship. Cancer J 2008, 14:425-428.

52. Hjermstad MJ, Fayers PM, Bjordal K, Kaasa S: Using reference data on quality of life - the importance of adjusting for age and gender, exemplified by the EORTC QLQ - C30 (+3. Eur J Cancer 1998, 34:138|-|389.

53. Cummins RA: On the trail of the gold standard for subjective well-being. Soc Indicators Res 1995, 35: 179-200.

\section{Pre-publication history}

The pre-publication history for this paper can be accessed here:

http://www.biomedcentral.com/1471-2407/9/222/pre pub
Publish with Bio Med Central and every scientist can read your work free of charge

"BioMed Central will be the most significant development for disseminating the results of biomedical research in our lifetime. "

Sir Paul Nurse, Cancer Research UK

Your research papers will be:

- available free of charge to the entire biomedical community

- peer reviewed and published immediately upon acceptance

- cited in PubMed and archived on PubMed Central

- yours - you keep the copyright 